\section{The Cause of Acute Rheumatism}

Dr. G. Arbour Stephens (Swansea) writes: Professor McNee is reported on p. 1089 of the Journal of November 27, 1937 , to have said that none of the hypotheses of the cause of acute rheumatism--streptococci, allergy, or filterable virus-was at all convincing. May I be allowed to draw attention to the last medical report to the Colonial Office in the Falkland lslands, in which, it is stated, there is permanently damp October weather with little sunshine, the houses are damp, the soil acid, the food so poor that the school children wear dentures, and septic tonsils full of streptococci are very prevalent. Whilst all the conditions necessary for the streptococci to act are present, yet there are no cases of acute rheumatism. Does not this dispose of the streptococcal theory? My belief is that acute rheumatism occurs in children of the "acid class" (whose $p \mathrm{H}$ is increased), the determining factor being a protozoon carried by an insect such as harvest bug, midge, or flea. On the Islands it is obvious the children are of the "acid class," but there are no insects, no fleas, bugs, or midges to bite these children, and so no protozoal parasite is carried.

\section{The Care of the Hypodermic Syringe}

No one will deny that the hypodermic syringe is one of the most important weapons in the doctor's armamentarium. Some may even think that its use is so thoroughly under stood that it is a work of supererogation to discuss it There are, however, a few points in its management which will bear emphasizing, even to a generation which is so familiar with its employment. It would be superfluous to labour the need for absolute asepsis, a lesson of the medical student's cradle. That this lesson has been thoroughly learnt is proved by the rarity of sepsis as a result of hypodermic medication. The next point is the advisability of causing the minimum of pain. Patients do not like being hurt, and here two considerations must be borne in mind The needle must be the finest possible and irreproachably sharp. It is not very difficult to keep a needle sharp provided that care is taken not to boil it for long periods Needles must be boiled, but they should only be immersed for a few seconds at a time. In these days it is more expensive to have needles resharpened than to buy new ones, which luckily are quite cheap, and if there is an extravagance which is pardonable on the part of a doctor it is in keeping himself well supplied with hypodermic needles of blameless acuity. Oily and viscous solutions, which are not readily drawn up into a narrow tube, often have to be injected through a needle of fine bore. But when such a solution is once introduced into the barrel of the syringe it can be forced out through a comparatively fine needle if sufficient finger pressure is supplied to the piston. For this reason it is often advisable for filling purposes to detach the needle, dip into the oily solution the glass nozzle, and draw the oil straight up into the barrel; after which the needle can be replaced and the desired dose administered through it. But care must be taken in doing this to hold the base of the needle with the finger and thumb firmly against the glass nozzle so that the firm pressure needed to force the oil through the narrow metal tube does not cause it to part company with the barrel, thus wasting the contents. From time to time one hears of cases where the needle breaks off and the distal portion becomes buried under the patient's skin. This accident, which has been known to lead to legal proceedings, is not really difficult to avoid. Fracture of the needle always takes place at its junction to the base. This is where corrosion is liable to set in, and is another argument for never using the same needle too long and too often; but in any case the danger of burying the needle in the patient can always be avoided by taking care not to plunge it in right up to the hilt Provided this precaution is taken, even if the needle should break there will be a projecting portion which can easily be grasped and drawn out. As regards the care of the glass barrel of the hypodermic syringe, the chief risk to its integrity occurs during the frequent boilings to which it must be subjected. The risk becomes much increased in the case of large syringes such as are used more and more nowadays for intravenous injections. Heat-resisting glass has been introduced for this reason, but syringes constructed of this material are much more expensive than others, and the life of ordinary glass barrels is much prolonged if care be taken to keep them from resting on the bottom of the sterilizer. Everyone knows that the barrel should never be boiled with the piston in situ, and it is a good plan to support the barrel, and the piston also if made of glass, in the metal frame invariably supplied by the makers for hold $\bar{z}$ ing them in their case. This ensures that the whole barrel is heated evenly and does not bump on the bottom of the sterilizer. It need hardly be said that the barrel of the syringe should be carefully cleaned every time it is used $\overrightarrow{\overline{\bar{T}}}$ but this is not always quite easy. Some of the solutions? and emulsions for which it may be employed are liable tog leave adherent deposits behind them. A great deal can be done with a pledget of cotton-wool grasped in a pair of finछ forceps, but even this is not always adequate to remove the last traces of a mercurial or bismuth cream. In such cases an effectual cleansing may usually be obtained by passing either benzine or petrol through the syringe, afterwards removing all traces of it with methylated spirit.

\section{Infection from Fresh-water Molluscs}

Dr. F. GoRdon Cawston writes from Durban, South Africa : The occasional reports of human infestation with trematodes and the regretted death of a conchologist from carcinoma. of the liver suggests that more use be made of the eosinophilcount in persons who handle fresh-water molluscs, and are $\vec{f}$ thus liable to attacks of free-swimming cercariae. Ignorant persons, and especially natives, should not be encouraged. to handle these molluscan hosts, and, where an obscure disease of the liver occurs in a collector, early attention to $\rightarrow$ the presence of infection may save a parasitic condition from becoming malignant.

\section{Osler in 1877-8}

Dr. A. D. WeBster (Edinburgh) writes: The note on "Osler's First Appearance in Print" in the Journal of November 20, 1937 (p. 1026), prompts me to send the following reminiscence. Osler was professor of physiology in McGill University, Montreal. His habit was to invite the class to come at 8 p.m. to the General Hospital mortuary to follow up any particular case in his wards that had died. He was at that time particularly interested in pernicious anaemia, and ofo cases of these he examined every organ of every system. The very old basement room is fixed on my memory. He would work to the end and we would preserve the parts? of the various tissues that he would examine later. How he toiled hour after hour-all of us nearly frozen; some- $\varrho$ times the hours went on beyond twelve before he would $\overrightarrow{\vec{D}}$ be satisfied. I see him now, his hands in the body and asking one of us to use his handkerchief for him, he hardly raising his head from his work. Such was dear Osler in those early days of his career.

\section{Convalescent Homes for the Poor}

A short sixpenny history of the Metropolitan Convalescent: Institution (14, Victoria Street, S.W.1) has been compiled by an anonymous authoress. The Institution was founded. nearly a hundred years ago by Theodore Monro, å promising young St. Bartholomew's physician, who died at the age of 24 . He was making his round at the hospital when he was touched by the distress of a woman who was about to be discharged to her slum dwelling, with no means $N$ of getting the country air which the doctors said was necessary to complete her recovery. Thereupon he sum- $\rightarrow$ moned a meeting in Wigmore Street, and the movement was started for providing homes wherein convalescent care for $\bar{N}$ members of the poorer classes might be afforded. To-day the Institution has well-equipped and pleasant homes at Walton-on-Thames, Bexhill, Broadstairs, and elsewhere, ando since its foundation 400,000 men, women, and children have enjoyed the benefit of such provision. The story of this? modest, unpretentious work was well worth recording.

\section{Disclaimer}

Dr. Michael Elyan writes: The use of my name in the public press in connexion with a letter published in last ${ }^{\mathbb{D}}$ week's British Medical Journal was without my consent.

\section{Corrigenda}

A strange blunder crept into an annotation on Robin and $\delta$ John Adair on December 25. last. In speaking of Generalo Wolfe we referred to. his death " on the Plains of Abraham outside Montreal." As all the. world should know, the Plains of Abraham lie close to the city of Quebec.

Our notice of Dr. John Rickman's General Selection from the Works of Sigmund Freud (January 15, p. 125) gave the name of the publishers incorrectly. The book is published by the Institute of Psycho-Analysis and the Hogarth Press. 